\title{
Letters
}

Website: bmj.com

Email: letters@bmj.com

\section{Length of penicillin treatment of streptococcal infections}

\section{Is seven days of treatment as effective as 10 days?}

EDITOR-Zwart et al recommend seven days of treatment for streptococcal infections as opposed to three days. ${ }^{1}$ For several decades we were educated to continue penicillin for such cases for no fewer than 10 days. ${ }^{2}$ The rationale was that streptococci must be eradicated to prevent rheumatic fever and that this was achievable only after 10 days of treatment. This was based on bacteriological, epidemiological, and clinical observations. The cost of oral penicillin is almost negligible, and I think we need more assurance to be persuaded to cut treatment to only seven days. Is there any study that will prove that treatment for seven days is as effective as treatment for 10 days for preventing rheumatic fever?

Dan Michaeli chairman, board of directors

Clalit Health Services, Tel Aviv 62098, Israe

michaeli@netvision.net.il

1 Zwart S, Sachs APE, Ruijs GJHM, Gubbels JW, Hoes AW, de Melker RA. Penicillin for acute sore throat: randomised double blind trial of seven davs versus three days treatment or placebo in adults. BMJ 2000;320:150-4. (15 January.)

2 Christie AB. Streptococcal infections-scarlet fever. In: Christie AB. Infectious diseases: epidemiology and clinical practice. Edinburgh: Livingstone, 1969: 983

\section{Antibiotics should not be used for self limiting illnesses}

EDITOR-I have two concerns about Zwart et al's article ${ }^{1}$ firstly, the methodology, and, secondly and more importantly, that it was conceived at all, in view of the issue of antibiotic use

The study had an unusually high number of exclusions (36.7\%), and $26.6 \%$ of the patients were not randomised. The secret code of treatment was broken at the request of the doctor or the patient. There was a faster resolution in the patients in the seven day treatment arm at two days than in the three day treatment arm at two days, despite identical treatment, and I am not convinced by the authors' explanation. A possibility concerning all the above points is that the randomisation was not successful, and therefore the results of the trial may not be secure.

However, these doubts are minor compared with the real issue, which is how we use the precious resource of antibiotics. Resistance to commonly used antibiotics is rising fast. ${ }^{2}$ The increasing use of antibiotics encourages resistant organisms in patients and in the community. ${ }^{3}$ In most cases antibiotics do not prevent complications. ${ }^{45}$ BMJ 1996;312:1454-6.
Finally, antibiotics have at best mild to modest benefit in pharyngitis.

If we continue to prescribe antibiotics for self limiting illnesses where there is small benefit at most, we will see an increase in the incidence of serious resistant infections such as pneumonia and meningitis, and in the mortality inevitably associated with these infections. Our resolution for the new millennium should be to stop prescribing antibiotics for minor self limiting conditions, to allow nature to heal these, and to save antibiotics for what they were designed for in the first place-serious and life threatening disease.

R Fleetcroft GP principal

The Medical Centre, Hemsby, Norfolk NR29 4EW rocdoc@user.scs-datacom.co.uk

1 Zwart S, Sachs APE, Ruijs GJHM, Gubbels JW, Hoes AW, de Melker RA. Penicillin for acute sore throat: randomised double blind trial of seven days versus three days treatment or placebo in adults. BMJ 2000;320:150-4. (15 January.)

2 Johnson AP, Speller DCE, George RC, Warner M, Domingue G, Efstratiou A. Prevalence of antibiotic resistance and serotypes in pneumococci in England and Wales: results of observational studies in 1990 and 1995

3 Arason VA, Kristinsson KG, Sigurdsson JA, Stefansdottir G, Molstad S, Gudmundsson S. Do antimicrobials increas the carriage rate of penicillin resistant pneumococci in children? Cross sectional prevalence study $B M J$ 1996;313:387-91.

4 Howie JGR, Fogro BA. Antibiotics, sore throats, and rheumatic fever.J R Coll Gen Pract 1985;35:223-4.

5 Taylor JL Howie JG. Antibiotics, sore throats and acute nephritis. JR Coll Gen Pract 1983;33:783-6.

\section{The data do not support the conclusions}

EDITOR-Zwart et al conclude from a placebo controlled randomised clinical trial that seven days of penicillin treatment for symptoms of acute sore throat is better than three days of treatment. ${ }^{1}$ In the accompanying editorial, one of the authors of the Cochrane review on antibiotics for sore throats ( 8 hours' benefit) is puzzled by the anomalous trial data that are presented.

As shown in figures 1 and 2 in Zwart et al's paper, the two primary outcome measures, resolution of symptoms and resolution of impaired daily activities, do not support those conclusions. The KaplanMeier plots show that at day 3 the resolution of symptoms in group 1 (seven days of penicillin) and group 2 (three days of penicillin) was significantly different, although both groups had received identical treatment. This unexplained twofold difference between the two penicillin groups carries over to misleading conclusions at day 7 . Importantly, outcomes in group 2 were almost identical with those for group 3 (placebo) for the entire study period.

The following results emerge by simply reformulating the research question as: what is the benefit of an additional four days of penicillin treatment, after the initial three days? From figure 1, in the seven day and three day groups, patients who were free of symptoms from day 3 through to day 7 were $37 \%$ v $15 \% ; 50 \%$ v $25 \% ; 70 \%$ v $43 \% ; 80 \%$ v $55 \%$; and $88 \%$ v $63 \%$ (thus differences in rates of cure are $22 \%, 25 \%, 27 \%, 25 \%$, and $25 \%$, respectively). As additional treatment in group 1 starts after day 3 , when this point is taken as the baseline reference the relative benefits are $3 \%, 5 \%, 3 \%$, and $3 \%$ for days 4 through 7 . Similarly, the other primary outcome measure, resolution of impaired activity (figure 2 ), shows relative benefits of $-2 \%$, $3 \%,-1 \%$, and $3 \%$, indicating no cumulative benefits from the extra four days of penicillin.

The authors need to explain the anomalous cure rate advantages for patients in group 1 at the day 3 baseline. My prime suspect is the unaccounted differences in prognostic factors such as "sore throat days" at entry among the three treatment groups, perhaps inadvertently favouring the seven day group. Also, use of well defined disease duration (onset, entry, and resolution) in life

\section{Advice to authors}

We prefer to receive all responses electronically, sent either directly to our website or to the editorial office as email or on a disk. Processing your letter will be delayed unless it arrives in an electronic form.

We are now posting all direct submissions to our website within 24 hours of receipt and our intention is to post all other electronic submissions there as well. All responses will be eligible for publication in the paper journal.

Responses should be under 400 words and relate to articles published in the preceding month. They should include $\leqslant 5$ references, in the Vancouver style, including one to the BMJ article to which they relate. We welcome illustrations.

Please supply each author's current appointment and full address, and a phone or fax number or email address for the corresponding author. We ask authors to declare any competing interest. Please send a stamped addressed envelope if you would like to know whether your letter has been accepted or rejected.

Letters will be edited and may be shortened.

bmj.com

letters@bmj.com 
table analyses may clarify these puzzling results.

Because the findings show equivalence of placebo to three days of penicillin in treating symptoms of acute sore throats, I see no reason for the Cochrane review of Del Mar and colleagues to be revised."

Erdem I Cantekin professor of otolaryngology University of Pittsburgh, School of Medicine, Children's Hospital of Pittsburgh, Pittsburgh, PA 15213, USA

lac32@juno.com

1 Zwart S, Sachs APE, Ruijs GJHM, Gubbels JW, Hoes AW, de Melker RA. Penicillin for acute sore throat: randomised double blind trial of seven days versus three days treatment or placebo in adults. $B M J$ 2000;320:150-4. (15 January.)

2 Del Mar C. Sore throats and antibiotics. BM 2000;320:130-1. (15 January.)

3 Del Mar C, Glasziou PP. Do antibiotics shorten the illnes of sore throat? In: Cochrane Collaboration. Cochrane Library. Issue 3. Oxford: Update Software, 1996.

\section{Life tables should be used with caution}

EDITOR-Both Fleetcroft and Cantekin point out a curious anomaly in life table analysis of recovery from acute illness. If the outcome measure chosen is the day on which symptoms last occurred rather than the end of the period of continuous symptoms, the kind of pattern observed in Zwart et al's study is almost unavoidable.

Imagine two patients-Bob in the seven day group and Paul in the three day group. Both get better after 24 hours, but Paul relapses on day 5 and recovers on day 7 . On the life table Bob seems to have recovered in the crucial first three days whereas Paul does not. Hence the early takeoff of the recovery curve in the seven day group. It does not in any way indicate allocation bias between the groups.

Perhaps the lesson is that life tables should be used with caution for data of this kind.

Peter Burke tutor in general practice

St Bartholomew's Medical Centre, Oxford

OX4 1XB

pdb@ermine.ox.ac.uk

1 Zwart S, Sachs APE, Ruijs GJHM, Gubbels JW, Hoes AW, de Melker RA. Penicillin for acute sore throat: randomised double blind trial of seven days versus three days treatment or placebo in adults. BMJ 2000;320:150-4. (15 January.)

\section{Care must be taken when extrapolating} data

EDITOR-The high prevalence of Centor criteria, fever, and quinsy (1:60 untreated) in Zwart et al's patients ${ }^{1}$ compared with patients from an unselective trial $(1: 400)$ or routine data ${ }^{23}$ confirms that pre-trial selection probably occurred, but details of pre-selection are a little unclear.

The severity of symptoms is not presented. Analgesic use was similar in the trial groups until day 4. Symptom relief after this-when symptoms are milder-may not be clinically important. This is supported by the lack of difference in time off school and work. The estimated 1-2 days' benefit must also be put in the context of the much larger data set from the systematic reviewsuggesting a benefit of 8 hours to half a day.

Perhaps the most important finding is that quinsy may be prevented. The
Cochrane review $w^{4}$ relies heavily $(76 \%$ of the weight) on a study of hospitalised patients given parenteral penicillin, where quinsy was common (1:18) - that is, not generalisable. The Centor criteria are crude because they were validated against the throat swab.

Nevertheless, the current trial supports the finding of another trial ${ }^{5}$ that crude antibiotic targeting to a clinical subgroup may prevent quinsy. However, since most patients were unwell with fever, targeting clinical subgroups may be no better than the general practitioner's overall judgment that the patients are not unwell systemically: these patients are at low risk irrespective of clinical signs $-20 \%$ of the 716 patients had three out of four Centor criteria, and the only patient who developed quinsy did not fulfil the Centor criteria. ${ }^{2}{ }^{3}$

Care must be taken in extrapolating efficacy trials to effectiveness in routine settings. Tablet counting and repeated examination may improve compliance, thus altering estimates of efficacy. With regard to symptoms, in an effectiveness trial (no repeated examination or tablet counting) patients with a very similar cluster to the Centor criteria, but who were well systemically, showed a benefit from antibiotics of a fraction of a day. ${ }^{2}$ With regard to complications, the computerised notes for five years in two contrasting practices documented nine cases of quinsy after presentation to the doctor: six received penicillin-so, preventing $100 \%$ of quinsy after sore throat, as implied by the efficacy trial results of Zwart et al and Dagnelie et al, ${ }^{5}$ is perhaps unlikely in everyday practice.

The results of Zwart et al's study must be put in the context of the presenting population, other evidence, and the possible difficulties of generalising evidence from efficacy trials to effectiveness in routine settings.

Paul Little MRC clinician scientist ps13@soton.ac.uk

\section{Ian Williamson senior lecturer}

Community Clinical Sciences (Primary Medical

Care Group), University of Southampton,

Aldermoor Health Centre, Southampton SO15 6ST

Greg Warner general practitioner

Nightingale Surgery, Romsey SO51 7QN

Michael Moore general practitioner

Three Swans Surgery, Salisbury SP1 1DX

1 Zwart S, Sachs APE, Ruijs GJHM, Gubbels JW, Hoes AW, de Melker RA. Penicillin for acute sore throat: randomised double blind trial of seven days versus three days treatment or placebo in adults. BMJ 2000;320:150-4. (15 January.)

2 Little PS, Williamson I, Warner G, Gould C, Gantley M, Kinmonth AL. An open randomised trial of prescribing strategies for sore throat. BMJ 1997:314:722-7.

3 Little PS, Gould C, Williamson I, Warner G, Gantley M, Kinmonth AL. Reattendance and complications in a andonised tial of prescribing strategies for sore throat: the medicalising effect of prescribing antibiotics. BMJ

4 Del Mar C, Glaziou P. Antibiotics for the symptoms and complications of sore throat. In: Cochrane Collaboration. Cochrane Library. Issue 3. Oxford: Update Software, 1998.

5 Dagnelie CF, Van der Graf Y, De Melker R, Touw-Otten FWMM. Do patients with sore throat benefit from penicillin? A randomised double blind placebo controlled clinical trial with penicillin $\mathrm{V}$ in general practice. $\mathrm{Br} J \mathrm{Gen}$ Prac 1996;46:589-93

\section{Authors' reply}

EDITOR-Michaeli comments on the risk of rheumatic fever when prescribing penicillin for fewer than 10 days. Indeed, in areas with poorer living conditions than in the Netherlands, a 10 day course of penicillin is needed. The distribution of the $\mathrm{T} / \mathrm{M}$ subtypes of group A streptococci among our patients and among healthy controls will be published shortly. Rheumatogenic subtypes were cultured in patients as well as in controls.

We were surprised by the difficulties experienced by Fleetcroft, Cantekin, and also by Del Mar in his editorial, ${ }^{2}$ concerning the methodological question of how to present the resolution of symptoms when they recurred during the first week of observation. A survival analysis gave us the most realistic picture of any difference in duration of symptoms between the treatment groups. Unfortunately, the results from the three day penicillin group (with $40 \%$ recurrences in the first week) had to be forced into the Kaplan-Meier straitjacket by using the definition of permanent resolution of symptoms. We do not agree with Cantekin's interpretation of our findings as we chose the endpoint of permanent resolution of symptoms. Burke's comments support our earlier explanation.

Little and colleagues focus on the generalisability of the results, which is the most relevant issue of any clinical trial. Indeed, the $21 \%$ of patients who did not meet the required number of clinical criteria was lower than the $50-60 \%$ rate we expected from the results of a previous study in the Netherlands. ${ }^{3}$ Probably the participating general practitioners underreported the number of patients with sore throats who were not eligible "at first sight."

We agree with Little et al that we studied a selected population. However, this was our intention. We tried to mimic the general practitioner's daily practice of patient selection. In this way, we were not surprised to find that penicillin was more effective than in Little et al's population, which probably included many patients with a viral infection. ${ }^{4}$ Interestingly, Little et al's open trial also included a subgroup of 94 ill patients with a symptom-sign complex similar to our complete patient group. Their table 3 indicates that antibiotics reduced the duration of sore throat in these patients.

Unlike Little et al, we are not worried that the artificial use of throat swabs and medication tray biased the recording of symptoms in the diary. How can this bias play a role if randomised patient groups are compared? Our trial was not designed to study whether penicillin would prevent quinsy or peritonsillar cellulitis. Nevertheless, the reason that the protective effect of penicillin in our patient group seemed to be at the same level as in some studies in the 1950s may again be explained by the strict inclusion criteria we used, selecting probably the most ill patients, most of them having a throat swab that was positive for streptococci. 
We agree with Little et al that the population studied should be taken into account when the findings are generalised. However, because we found important and relevant effects of penicillin, we feel free to reverse the association between result and population. To incite further discussion on the management of sore throat in adults we therefore recommend for other routine settings, such as the primary care setting in the United Kingdom, the selection criteria that we used in our study and that are also used in Dutch daily practice.

Fleetcroft and Little et al fear that penicillin will be used as a routine drug in a routine setting, thus leading to medicalised patients and resistant strains. We share their fear, but believe that doctors and patients can make a well balanced decision only when they are informed not only about the costs and adverse effects of antimicrobial treatment, but also about the benefits.

Sjoerd Zwart general practitioner

Alfred Sachs general practitioner

Arno Hoes professor of clinical epidemiology

Ruut de Melker professor of general practice

Julius Center for General Practice and

Patient-oriented Research, University Medical

Center Utrecht, 3584 CG Utrecht, Netherlands

Gijs Ruijs clinical microbiologist

Laboratory for Microbiology and Infectious

Diseases, Isala Clinics, 8021 AM Zwolle,

Netherlands

Jan Gubbels statistician

Organisation for Advice on Research and

Policymaking, 5361 JZ Grave, Netherlands

1 Zwart S, Ruijs GJHM, Sachs APE, van Leeuwen WJ Gubbels JW, de Melker RA. Beta-hemolytic streptococe solated from acute sore throat patients: cause or coincidence? A case-control study in general practice Scand J Infect Dis 2000 (in press).

2 Del Mar C. Sore throats and antibiotics. $B M J$ 2000;320:130-1. (15 January.)

3 Dagnelie CF, Touw-Otten FWMM, Kuyvenhoven MM, Rozenberg-Arska M, de Melker RA. Bacterial flora in patients presenting with sore throat in Dutch general practice. Fam Pract 1993;10:371-7.

4 Little PS, Gould C, Williamson I, Warner G, Gantley M, Kinmonth AL. An open randomised trial of prescribing strategies for sore throat. BMJ 1997;314:722-7.

5 Graham A, Fahey T. Sore throat: diagnostic and therapeutic dilemmas. BMJ 1999;319:173-4.

\section{Treating children with sleep disorders}

\section{Children with breathing difficulties are being overlooked}

EDITOR-I was disappointed to see that once again children with sleep disorders are being lumped into a homogeneous group of children with "behavioural" problems, then "studied" without using polysomnography. I think it's presumptuous and dangerous to think that every child who has trouble sleeping has a behavioural problem. Few physicians are aware that breathing difficulty can cause night waking and bedtime resistance, and it is because of studies like that of Ramchandani et al.

Doctors don't look for sleep disorders properly, don't know much about them, and are told repeatedly that behavioural treatments are the appropriate treatment. This is wrong unless we can guarantee that the children have behavioural problems. A study looking at obese children using polysomnography diagnosed unsuspected obstructive sleep apnoea in $75 \%$ of the children studied-meaning the physicians examining the children picked up only 1 in 4 cases. It therefore seems a big leap of faith not to be doing polysomnography more often. Some of the children waking at night could have upper airways resistance syndrome, which can also cause sleep problems. Most doctors can barely take a proper history for sleep disorders, let alone diagnose a subtle case of upper airways resistance syndrome causing repeated night waking or bedtime resistance. Studies like that of Ramchandani et al certainly don't help because they take the emphasis away from finding a "real physiological" problem and on to stress behavioural modification.

Before we continue to send physicians out to behaviourally modify breathing difficulties or other subtle causes of sleep disorders that can mimic behavioural problems, we need to do polysomnography on these children

Mary Fay general paediatrician

2303 Glenview Avenue, Park Ridge, IL 60068, USA mfay@enteract.com

1 Ramchandani P, Wiggs L, Webb V, Stores G. Systematic review of treatments for settling problems and night waking in young children. BMJ 2000;320:209-13. (22 January.)

\section{Night waking is natural behaviour}

EDITOR-The basic assumption of the study of Ramchandani et al that very young children should settle down to sleep away from their parents and not be seen or heard from again until morning is flawed. ${ }^{1}$ In many non-Western societies this type of sleep pattern would be seen as an aberration.

Anthropologist Carol Wortham of Emory University in Atlanta uncovered a variety of sleep patterns in 10 traditional hunter-gatherer societies, none of which coincide with our society's current ideal of sleeping alone without waking alone for the entire night. ${ }^{2}$ Perhaps some amount of night waking in children and their desire for comforting by parents are both natural and healthy. Our difficulty in combating this behaviour may arise because we are struggling against nature and basic human biology. We must be careful not to confuse that which is desirable for human health with that which is merely a current preference and expectation of our society.

Zan Buckner breast feeding counsellor 4294 Shihmen Drive, Antioch, TN 37013, USA

1 Ramchandani P, Wiggs L, Webb V, Stores G. Systematic review of treatments for settling problems and night waking in young children. BMJ 2000;320:209-13. (22 January) 2 Wothman CM, Melby MK. Toward a comparative developmental ecology of human sleep. In: Carskadon MA, ed Adolescent sleep patterns: biological, social, and psychological influences. New York: Cambridge University Press (in press).

\section{Early intervention increases sleep times} in young babies

EDITOR-Ramchandani et al's systematic review of treatments for established infant sleep problems shows that behavioural interventions improve sleep patterns. ${ }^{1}$ The authors reference the frequency of sleep disorders as 20\% in children aged $1-3$ years, the tendency for these problems to be persistent, and their associations with behavioural difficulties and family disharmony. Other authors quote the frequency of sleep disturbance to be as high as 35\%. Armstrong reported that $60 \%$ of parents were getting up at night when their child was 12 months old, and half of them were rising three times a night or more.

We tested the impact of a short behavioural intervention in normal neonates in a randomised trial (submitted for publication). In all, 269 families with normal newborn singletons were recruited within the first three weeks of life and were randomly allocated to intervention or control groups. Families in the intervention group received a single 45 minute tutorial from a research nurse. The tutorial emphasised that in children who were healthy and gaining weight satisfactorily sleep achievement should be regarded as a "learnt skill" influenced by environmental factors or "cues of sleep." Parents were encouraged to avoid fatigue in their infants by not overhandling and to establish cues of sleep independent of the parent. Outcomes were measured through a sleep diary at 6 weeks of age.

All aspects of sleep performance were significantly improved in the intervention group. Total sleep increased by almost nine hours a week at 6 weeks $(\mathrm{P}<0.0001)$. The proportion of infants sleeping 15 hours a day was $61 \%$ in the intervention group and $28 \%$ among controls $(\mathrm{P}<0.0001) .78 \%$ of sleep cycles among infants in the intervention group included over eight hours of night sleep, compared with $61 \%$ of cycles among controls $(\mathrm{P}<0.0001)$.

Although the technique emphasised minimising parental handling at sleep time, there was no difference in the amount of crying between the groups. Follow up at 3 months of age showed that improvements were maintained. Our findings therefore support, and add to, those reported in the systematic review.

Although Ramchandani et al did a well designed systematic review, our unpublished work was not identified, and it would be unreasonable to expect it to have been. This experience therefore supports the calls for a register of planned and ongoing randomised trials, ${ }^{4}$ and it also shows the importance of regularly updating systematic reviews through the Cochrane Collaboration as new evidence becomes available.

Brian Symon senior lecturer bsymon@medicine.adelaide.edu.au

John Marley professor of general practice

Department of General Practice, University of Adelaide, South Australia

James Martin director of respiratory medicine Adelaide Women's and Children's Hospital Adelaide, South Australia

1 Ramchandani P, Wiggs L, Webb V, Stores G. Systematic review of treatments for settling problems and night waking in young children. BMJ 2000.320.209-13. (22 January.) 2 Johnso MC Infant and toddler sleep A telephone surve Johnson MC. Infant and toddler sleep. A telephone survey of parents in one community. Dev Behav Pediatrics
1991;12:108-14. 
3 Armstrong KL, Quinn RA, and Dadds MR. The sleep patterns of normal children. Med J Aust 1994;161:202-6.

4 Horton R, Smith R. Time to register randomised trials BMJ 1999;319: 865-6. (2 October.)

\section{Treatment of child sleeping problems} and the quality of trials are important

EDITOR-Ramchandani et al's finding that behavioural treatments are effective in treating sleep problems will inform practice but omitted three important issues. ${ }^{1}$

Firstly, two of the nine identified treatment studies included infants as young as 1 month. Infants are not born with the ability to sleep through the night, but sleep patterns are entrained by environmental cues. ${ }^{2}$ Waking at night in the early months of life is an adaptive behaviour to secure frequent feeding and to allow for rapid weight gain and brain growth. Sleeping through the night in the early weeks of life and a lack of waking for feeds is likely to put vulnerable infants (such as preterm infants or poor feeders) at risk of poor appetite development and suboptimal growth. ${ }^{3}$ Behavioural treatments for night waking should thus not start before 6 months of age.

Secondly, infants who are breast fed do sleep less during 24 hours $^{4}$ and are more likely to wake at night than bottle fed infants. ${ }^{3}$ Parents should be informed that breast feeding does not impede infants from learning to sleep through the night. Early routines, avoidance of feeding the infant into "sleep submission," and the use of focal feeds can, however, help to reduce the stress of night time breast feeding.

Thirdly, sleeping problems often coexist with excessive crying or feeding difficulties. ${ }^{2}$ Parents with infants with multiple difficulties are more likely to seek help. Studies are still required to establish that behavioural interventions are effective in infants with multiple problems.

Finally, quality criteria developed for drug trials were used to judge the quality of the behavioural treatments. ${ }^{1}$ These include double blinding to guard against performance bias and randomisation to exclude selection bias. Double blinding is not possible in behavioural studies. Therapists have to know what they are doing and why. Randomisation in small samples (less than 30) is often not effective as the effect sizes may become inflated because of outliers and there may be pretreatment differences. Quality ratings are there to judge the internal validity of a trial-that is, the confidence that the cause of any observed differences is due to the treatment conditions. The increasing use of "off the shelf" criteria for judging the quality of behavioural treatments is of doubtful validity. There are specific methods to guard against performance bias in behavioural trials such as the investigation of generalised placebo effects. Checking and controlling for a range of pretreatment differences may be as important as randomisation itself. ${ }^{5}$

Dieter Wolke research professor of psychology Department of Psychology, University of Hertfordshire, Hatfield AL10 9AB

D.F.H.Wolke@herts.ac.uk
1 Ranchandani P, Wiggs L, Webb V, Stores G. A systematic review of treatments for settling problems and night waking in young children. BMJ 2000;320:209-13. (22 January.) Wolke D, Meyer R, Ohrt B, Riegel K. Co-morbidity of cry ing and feeding problems with sleeping problems in infancy: concurrent and predictive associations. Early Dev Parenting 1995;4:191-207.

3 Wolke D, Söhne B, Riegel K, Ohrt B, Österlund K. An epidemiological study of sleeping problems and feedin experience of preterm and fullterm children in south Finland: comparison to a south German population sample. Pediatrics 1998;133:224-31.

4 Lucas A, St James-Roberts I. Crying, fussing and colic behaviour in breast- and bottle-fed infants. Early Hum Dev 1998;53:9-18

DB. The efficacy of psychological, edtcational, and behavioural treatment. Am Psychologist
conto 1993;48:1181-209.

\section{Authors' reply}

EDITOR-We are aware of Fay's general point that it is the underlying sleep disorder rather than the presenting complaint at which treatment should be directed. She suggest that polysomnography is indicated for all children presenting with a sleep problem. We consider it more important that careful clinical inquiry is made to identify children with wide ranging physical conditions or other sleep disorders associated with sleep disturbance rather than to focus on the few conditions that can be identified by polysomnography. Furthermore, the appropriate diagnostic criteria for paediatric sleep related breathing disorders are being frequently refined (adult criteria, which have been used in the past, are not appropriate), and polysomnography is just one of the clinical investigations that may be required to diagnose these conditions. ${ }^{\prime}$

All but one of the studies in our review (one study did not explicitly state screening procedures) included a broad assessment of the children's overall sleep pattern and medical history, including careful screening for symptoms suggestive of other sleep disorders and medical conditions. In the absence of any clinical signs of sleep related breathing disorders, and with clear indication of behavioural aspects maintaining the child's sleep problem, it would be difficult to justify (both to parents and to healthcare providers) the need for potentially unhelpful polysomnographic assessment.

Fay suggests that waking at night and bedtime resistance may themselves be a clinical sign of a sleep related breathing disorders, arguing that a large proportion of children with obstructive sleep apnoea also have such problems. This link is contentious and disputed, ${ }^{1}$ and, even if it is accepted it does not follow that a large proportion of children with night waking and bedtime resistance also have obstructive sleep apnoea. The prevalence figures make it more likely that children with obstructive sleep apnoea form a small subset of those with behavioural sleeplessness. Research suggests that a detailed sleep history would alert clinicians to which patients are likely to fall into this group. ${ }^{1}$ A phased approach to both assessment and treatment is needed to ensure maximum diagnostic accuracy and to minimise unnecessary procedures. ${ }^{2}$

Buckner is right that assumptions about children's sleep are culturally determined. However, the reality that parents and health- care professionals face within a Western society is that it is often considered desirable for children to sleep independently. In this context continuing sleep disturbance in a young child has many adverse effects on both the child and his or her parents or carers. Given this, seeking the best ways of helping such parents or carers find solutions to their difficulty seems a reasonable pursuit.

We agree with Symon et al that a register of planned and ongoing trials, and the updating of systematic reviews through the Cochrane Collaboration are important. We have had discussions with the Cochrane Collaboration to that end. Nevertheless, their study would not have been included in our review as we focused on children with an established sleep problem. Another systematic review has dealt with studies similar to theirs. ${ }^{3}$

We agree with the first three points made by Wolke. His fourth, about the choice of quality criteria, identifies a dilemma facing anyone conducting a systematic review: should they describe each study and its strengths and weaknesses in detail or use a quality rating scale as a form of shorthand? Within a journal it is rarely possible to describe each study in detail, and it can also make for difficult reading. The use of quality criteria makes comparison of trials easier to understand, but at the cost of inevitable loss of accuracy. We would welcome the development of quality criteria more appropriate for psychological treatment trials. Until that time use of well standardised quality ratings represents the best compromise.

Luci Wiggs research psychologist

Gregory Stores professor

University of Oxford Section of Child and

Adolescent Psychiatry Park Hospital for Children,

Oxford OX3 7LQ

Paul Ramchandani specialist registrar

Child and Family Psychiatric Service, Sue Nicholls Centre, Manor House, Aylesbury HP20 1EG

Vicky Webb general practitioner

Florence Nightingale House, Aylesbury HP21 8AI

1 Carroll JL, Loughlin GM. Obstructive sleep apne syndrome in infants and children: clinical features and pathophysiology. In: Ferber R, Kryger M, eds. Principles and practice of sleep medicine in the child. Philadelphia: W B Saun5:163-91.

2 Stores G. Practitioner review: assessment and treatment of sleep disorders in children and adolescents. J Child Psychol Psychiatry 1996;37:907-25.

3 Renfrew MJ, Lang S. Influencing the sleep patterns of exclusively breastfed infants. In: Cochrane Collabortion. Cochrane Library. Oxford: Update Software, 1994.

4 Jadad AR, Moore RA, Carroll D, Jenkinson C, Reynolds DJM, Gavaghan DJ, et al. Assessing the quality of reports of randomized clinical trials: is blinding necessary? Comtrol Clin Trials 1996;17:1-12.

\section{Recent advances in intensive care}

\section{Percutaneous tracheostomy may not be more effective than open technique}

EDITOR-In his review of recent advances in intensive care Stott emphasised the efficacy of percutaneous tracheostomy over the conventional open surgical approach. ${ }^{1}$ We agree that percutaneous tracheostomy may indeed be the preferred method in selected cases, 
but it is invariably not used in patients who present anatomical challenges such as a short, thick neck; goitre; a history of neck surgery; or a concurrent coagulopathy. Such difficult cases probably represent about a quarter of an average population requiring tracheostomy.

We disagree with Stott's assertion that the incidence of complications has been shown to be lower with percutaneous tracheostomy than with open surgical techniques. The paper quoted in support of this statement-by Hill et al-describes the results of 356 percutaneous procedures performed in a single unit over four years. ${ }^{2}$ No direct comparison is made with open tracheostomies, and the authors do not report the numbers and type of patients deemed unsuitable for percutaneous tracheostomy and referred for open procedures. The six previous independent series quoted that detailed complication rates for open tracheostomy were published on average nearly 20 years earlier, and a conclusion was reached by comparison with these older studies.

Stott fails to mention Dulguerov et al's meta-analysis reported in 1999, which showed that percutaneous tracheostomy is associated with a higher prevalence of certain complications. ${ }^{3}$ Their comparison of recent surgical tracheostomy trials $(n=21$; 3512 patients) and percutaneous tracheostomy trials $(\mathrm{n}=27 ; 1817$ patients) shows that perioperative complications are more common with the percutaneous technique $(10 \%$ v 3\%), whereas postoperative complications occur more often with the surgical technique $(10 \% \quad v \quad 7 \%)$. The bulk of the differences is in minor complications, except perioperative death $(0.44 \% v 0.03 \%)$ and serious cardiorespiratory events $(0.33 \% v$ $0.06 \%)$, which were much higher with the percutaneous technique. These authors also noted significantly fewer complications in recent studies compared with older ones.

In the present state of knowledge it would seem unethical to mount a large double blind trial comparing the two techniques as this would subject about a quarter of patients, who would usually be deemed unsuitable for a percutaneous technique, to an increased risk of complications. It is likely that such patients will continue to be referred for open tracheostomy. While this selection bias continues, it is misguided to state that percutaneous tracheostomy holds fewer risks than the open technique.

Natalie Brookes specialist registrar

David Howard senior lecturer

Royal National Throat, Nose and Ear Hospital,

London WC1X 8DA

1 Stott S. Recent advances in intensive care. $B M J$ 2000:320:358-61. (5 February)

2 Hill BB, Zweng TN, Maley RH, Charash WE, Toursarkissian B, Kearney PA. Percutaneous dilatational tracheostomy: report of 356 cases. J Trauma 1996;41:238-43.

3 Dulguerov P, Gysin C, Perneger TV, Chevrolet JC. Percutaneous or surgical tracheostomy: a meta-analysis. Crit Care Med 1999;27:1617-25.

\section{Author's reply}

EDITOR-Brookes and Howard's point that not all patients are suitable for a percutaneous tracheostomy is well made, but the figure quoted of $25 \%$ is conjecture and not referenced. As I cannot find any data to produce a figure of my own I will not, but I do question their final paragraph when they state that because of this figure a double blind trial would be unethical. This is curious as nowhere in my article did I suggest that one should be performed.

The meta-analysis referenced looks only at studies published up to 1996 and compares four different percutaneous techniques with surgical tracheostomies performed in two different eras. ${ }^{1}$ As most of the deaths occurring with percutaneous tracheostomy occur with a non-dilatational technique it would seem prudent to exclude these from the analysis.

There have been three published prospective trials comparing dilatational percutaneous tracheostomy with open surgical techniques..$^{2-4}$ These show complication rates for percutaneous tracheostomy to be as low as or lower than those for the surgical technique. This, coupled with the reduced cost avoidance of moving critically ill patients, and low long term complication rates, means that I can still conclude that percutaneous tracheostomy is a significant recent advance.

Stephen Stott consultant in anaesthesia and intensive care

Grampian University Hospitals Trust, Aberdeen AB25 2ZN

s.a.stott@abdn.ac.uk

1 Dulguerov P, Gysin C, Perneger TV, Chevrolet JC. PercutaDeous or surgical r, Perneger neous or surgical trac
Med 1999:27:1617-25.

Med 1

2 Hazard P, Jones C, Benitone J. Comparative clinical trial of standard operative tracheostomy with percutaneou racheostomy. Crit Care Med 1991;19:1018-2

3 Crofts SL, Alzeer A, McGuire GP, Wong DT, Charles D. A comparison of percutaneous and operative tracheostomies in intensive care patients. Can J Anaesth 1995;42: $775-9$

4 Friedman Y, Fides J, Mizock B, Samuel J, Patel S, Appavu S, et al. Comparison of percutaneous and surgical tracheostomies. Chest 1996;110:480-5.

\section{More still needs to be known about} immunonutrition

EDITOR-I have concerns over one section in Stott's article on recent advances in intensive care. ${ }^{1}$ These concerns relate to the paragraphs on nutrition, and particularly the key points box on page 358 ; there it is stated that recent work has shown that omega 3 polyunsaturated fatty acids improve mortality in critical illness.

The question of immunonutrition is complex, and the different nutrients used in clinical trials can have different, and opposing, effects on the immune system. For example, L-arginine and glutamine stimulate a variety of immune functions. ${ }^{2}$ In contrast, omega 3 and omega 6 fatty acids inhibit a variety of immune functions. ${ }^{23}$

The timing of administration of these nutrients may therefore be critically important: although it is generally believed that stimulation of the immune system is beneficial in critically ill patients, this may not always be the case. For example, in certain patients (those with adult respiratory distress syndrome or multiorgan failure) in whom the cytokine cascade and production of inflam- matory mediators has been suggested to be excessive, administration of omega 3 and omega 6 fatty acids would be beneficial in reducing production of these mediators.

In terms of immunonutrition affecting clinical outcome in critical illness, a recent critical analysis of all the randomised controlled trials in which L-glutamine was given found little evidence to support its routine clinical use. ${ }^{4}$ A recent meta-analysis found that giving combinations of immunomodulatory nutrients reduced infectious complications but not mortality.

When the use of nutrition in critically ill patients is being considered, these considerations must be taken into account. It is still not clear which patients will benefit from being fed these immunomodulatory nutrients and which may not.

Steven D Heys professor of surgical oncology and nutritional oncology

University of Aberdeen, Aberdeen AB24 3UX s.d.heys@abdn.ac.uk

1 Stott S. Recent advances in intensive care. BMJ 2000;320:358-61. (5 February.)

2 Heys SD, Gough DB, Khan L, Eremin O. Nutritional pharmacology and malignant disease: a therapeutic modality. BrJ Surg 1996;83:608-19.

3 Almallah YZ, El-Tahir A, Heys SD, Richardson S, Eremin O. Distal procto-colitis and n-3 polyunsaturated fatty acids: the mechanism(s) of natural cytotoxicity inhibition. Eur J Clin Invest 2000;30:58-65.

4 Heys SD, Ashkanani F. Glutamine. Br J Surg 1999;86:28990.

5 Heys SD, Walker LG, Smith I, Eremin O. Enteral nutritional supplementation with key nutrients in patients with critcal illness and cancer: a meta-analysis of with $1999 \cdot 929 \cdot 467-77$

\section{Genetic factors and osteoporotic fractures in elderly people}

Twin data support genetic contribution to risk of fracture

Editor-Kannus et al suggest from prospective data collected on Finnish twins that genetic factors are of only minor importance in explaining the population occurrence of osteoporotic fracture, particularly in women.

The evidence given to support this is the relatively small excess in concordance in monozygotic twins compared with dizygotic twins. But it is well recognised that twin concordances may be misleading unless the underlying prevalence of a disease is taken into account. ${ }^{2}$ For example, a small absolute differenceinmonozygotic compared with dizygotic concordance is more suggestive of a genetic effect for a trait that is relatively rare (such as fracture) than for one that is common. The data thus warrant closer scrutiny.

We have estimated the relative contribution of genetic, shared environmental, and unique environmental components to the variation in susceptibility to fracture in these twins from the data provided. The analysis was conducted using a variance components approach with the statistical software Mx. ${ }^{3}$ The method assumes that risk of fracture is determined by a continuous underlying liability and is a plausible assumption for this trait. ${ }^{4}$ 
As expected, the results show significant evidence of familial resemblance in the risk of fracture in both male and female twins. In female twins, despite the nationwide sampling frame, there is insufficient statistical power in this study to distinguish between models containing components in which this clustering is attributed to genetic factors alone, the shared family environment of the twins, or the combination of the two. In a model in which the only contribution is from geneticanduniqueenvironmentalfactors,genetic factors account for $36 \%$ of the variance in the liability to fracture at any body site.

In male twins the familial resemblance is explained by a significant contribution from genetic factors but not by the shared family environment, with genetic factors accounting for $35 \%$ of the variation in liability to fracture. A greater genetic contribution is also suggested at the spine in table $\mathrm{A}$ in Kannus et al's study (bmj.com/cgi/content/ full/319/7221/1334/DC1), although inference is limited by the small numbers of concordant pairs and the lack of data on differences between the sexes in rate of fracture. In contrast to the conclusion reached by the authors, these data show that genetic factors contribute to a third of the liability to osteoporotic fracture in men and are entirely compatible with the hypothesis that genetic factors contribute to a similar extent in women. The data suggest that there may be differences in the nature of the genetic risk in men and women and at different body sites that merit further study.

Alex J MacGregor Arthritis Research Campaign senior fellow alex.macgregor@kcl.ac.uk

Harold Snieder genetic epidemiologist

Tim D Spector director

Twin Research and Genetic Epidemiology Unit, S Thomas's Hospital, London SE1 7EH

1 Kannus P, Palvanen M, Kaprio J, Parkkari J, Koskenvuo M. Genetic factors and osteoporotic fractures in elderly
people: prospective 25 year follow up of a nationwide cohort of elderly Finnish twins. BMJ 1999;319:1334-7. (20 cohort of elde

2 Smith C. Concordance in twins: methods and interpretation. Am J Hum Genet 1974;26:454-66.

3 Neale MC. Mx: statistical modeling. 4th ed. Richmond, VA Neale MC. Mx: statistical modeling. 4th ed. Richmond, VA:
Department of Psychiatry (Box 126 MCV, Richmond, VA 23298, USA), 1997.

Falconer DS. Introduction to quantitative genetics. Harlow:

4 Falconer DS. Introduction to quantitative
Longman Scientific and Technical, 1989.

Study supports possibility of differences in development of osteoporotic fractures between sexes

EDITOR-Kannus et al report their large, long term prospective study analysing the genetic predisposition of osteoporotic fractures in elderly Finnish twins. ${ }^{1}$ It is important to note that whereas the concordance rate for fractures was indeed not strikingly different between monozygotic and dizygotic twin pairs in women, there was a fourfold difference in men.

In their electronic response to the article [published here in the paper journal, above] MacGregor et al have estimated the relative contribution of genetic components on the basis of the data provided; they found a strong role for genetic factors in men but not women. ${ }^{2}$ Previous studies have pointed to possible differences in the main regula- tory factors in the development of low bone mineral density and osteoporotic fractures between the sexes. We suggest that the data presented by Kannus et al could be interpreted as further evidence supporting this hypothesis.

Bone density is suggested to be multifactorially regulated and polygenically determined. Underlying diseases such as inflammatory bowel disease and several drugs such as glucocorticosteroids can modulate and enhance the effect of genetic factors on the development of osteoporotic fractures. For example, our studies have shown that the allele 2 at the AvaI polymorphism in the interleukin-1 $\beta$ gene-related to a higher production of the cytokine-is associated with a subgroup of patients (those with the nonfistulising form of Crohn's disease). ${ }^{3}$ Additionally, we have found a strong correlation between this polymorphism and bone mineral density in patients with inflammatory bowel diseases but not in healthy controls. We also found a difference between the two sexes: the association at the lumbar spine was present only in men. ${ }^{4}$

Bone loss at the cortical and trabecular bones seems to be influenced by several physiological and other elements such as the menopause or use of corticosteroids. Therefore, analysing data after screening for the often "silent" vertebral fractures could further modify Kannus et al's results concerning the importance of the genetic background.

Bone mineral density is a key predictor of osteoporotic fractures. To judge the weight of genetic influence it would be important to compare concordance rates in the groups with low and high $\mathrm{Z}$ score values. We suggest that studies in well defined subgroups of patients may help to define those conditions in which genetic background has a high prognostic value for the risk of osteoporotic fractures.

Andrea Nemetz assistant research assistan Semmelweis University of Medicine, 2nd Department of Medicine, Budapest 1088, Hungary Amado Salvador Pena professor of gastrointestinal immunology

Free University Hospital, Amsterdam, Netherlands as.pena@azvu.nl

Model fitting for data on osteoporotic fractures among monozygotic and dizygotic twin pairs of Finnish twin cohort

\begin{tabular}{|c|c|c|c|c|c|c|c|}
\hline \multirow[b]{2}{*}{ Model } & \multicolumn{4}{|c|}{ Proportion of variance accounted for by: } & \multirow[b]{2}{*}{$\chi^{2}$ value } & \multirow[b]{2}{*}{$P$ value } & \multirow[b]{2}{*}{$\begin{array}{c}\text { Akaike's } \\
\text { information } \\
\text { criterion }^{*}\end{array}$} \\
\hline & $\begin{array}{c}\text { Additive } \\
\text { genetic } \\
\text { effects (A) }\end{array}$ & $\begin{array}{l}\text { Non-additive } \\
\text { genetic } \\
\text { effects (D) }\end{array}$ & $\begin{array}{c}\text { Shared } \\
\text { environmental } \\
\text { effects (C) }\end{array}$ & $\begin{array}{c}\text { Unique } \\
\text { environmental } \\
\text { effects (E) }\end{array}$ & & & \\
\hline \multicolumn{8}{|l|}{ Men } \\
\hline $\mathrm{E}$ & & & & 1.000 & 15.28 & 0.009 & 5.28 \\
\hline$\overline{\mathrm{CE}}$ & & & 0.216 & 0.784 & 7.22 & 0.13 & -0.78 \\
\hline$\overline{\mathrm{AE}}$ & 0.347 & & & 0.653 & 3.28 & 0.51 & -4.72 \\
\hline ACE & 0.347 & & 0.000 & 0.653 & 3.28 & 0.35 & -2.72 \\
\hline$\overline{\mathrm{ADE}}$ & 0.000 & 0.398 & & 0.602 & 1.83 & 0.61 & -4.17 \\
\hline \multicolumn{8}{|l|}{ Women } \\
\hline $\mathrm{E}$ & & & & 1.000 & 26.68 & 0.00 & 8.44 \\
\hline$\overline{\mathrm{CE}}$ & & & 0.260 & 0.740 & 0.57 & 0.97 & -7.44 \\
\hline$\overline{\mathrm{AE}}$ & 0.367 & & & 0.633 & 1.35 & 0.85 & -6.45 \\
\hline$\overline{\mathrm{ACE}}$ & 0.146 & & 0.168 & 0.686 & 0.10 & 0.99 & -5.91 \\
\hline$\overline{\mathrm{ADE}}$ & 0.367 & 0.000 & & 0.633 & 1.35 & 0.72 & -4.65 \\
\hline
\end{tabular}

*Combines information on statistics of goodness of fit (the lower the $\chi^{2}$ value the better the fit) and simplicity of model (the best model usually being the one with the lowest value).
1 Kannus P, Palvanen M, Kaprio J, Parkkari J, Koskenvuo M people: prospective 25 year follow up of a nationwide cohort of elderly Finnish twins. BMJ 1999;319:1334-7. (20 November.

2 MacGregor AJ, Snieder H, Spector TD. Twin data support a genetic contribution to fracture risk [electronic response to Kannus et al. Genetic factors and osteoporotic fractures in elderly people: prospective 25 year follow up of a 1999. www.bmj.com/cgi/eletters/319/7221/1334\#EL1 (accessed 5 April).

3 Nemetz A, Nosti-Escanilla MP, Molnár T, Köpe A, Kovács A, Fehér J, et al. IL1B gene polymorphisms influence the course and severity of inflammatory bowel disease. Immunogenetics 1999;49:527-31.

4 Nemetz A, Zágoni T, Tóth M, Kovács A, Nosti-Escanilla MP, García-González MA, et al. Interleukin-1 gene polymorphisms stimulate bone loss in inflammatory bowel diseases. Gut 1999;45(suppl V):A15.

\section{Authors' reply}

EDITOR-On the basis of our published data MacGregor et al computed estimates of genetic variance in liability to osteoporotic fractures. Our original manuscript had the same modelling analysis (table), but after a recommendation by a reviewer and the $B M$ /s editorial committee we omitted the modelling part of the study from the paper.

MacGregor et al's interpretation of the results of the modelling differs from ours. We emphasise three points. Firstly, no matter what model is used to examine our data, the liability to osteoporotic fracture has a large environmental component (always $\geqslant 60 \%$ ) in both sexes. This is not clearly pointed out by MacGregor et al.

Secondly, we do not want to say that "genetic factors are of only minor importance in explaining the population occurrence of osteoporotic fracture"; we want to say that they are not strongly related to it. We thus want to draw attention to the fact that although genetic factors have a dominant role in explaining interindividual variation in bone density, the result is quite different (that is, unshared environmental effects become dominant) when the end fractures, the true end point of the entire osteoporosis problem.

Thirdly, in women MacGregor et al highlight the AE model (the only contribution to risk of fracture is from genetic and unique environmental factors), in which Genetic factors and osteoporotic fractures in elderly point is changed from bone tissue to 
genetic factors account for about $36 \%$ of the variance in liability to fracture, but they ignore the fact that the CE model (includes no genetic effects to explain twin similarity in liability to fracture) gave a better fit to the data. It has to be remembered that the statistical power of the study was not sufficient to differentiate between these competing explanations. Clearly, more incident cases are needed for more definitive conclusions.

Finally, we agree with MacGregor et al that there may well be differences in the nature of the genetic risk of osteoporotic fracture between men and women and at different body sites. Further follow up of our cohort and examination of the situation in other populations are thus needed.

With regard to Nemetz and Pena's letter, analysis of "silent" vertebral fractures will not change the result of the clinically more important non-vertebral fractures. We do not fully agree with the authors' statement that bone density is a key predictor of osteoporotic fractures. Many recent epidemiological studies indicate that falling is the strongest single predictor of these fractures, and bone mineral density is an independent predictor of only moderate importance. When this fact becomes more widely recognised, the framework of fracture prevention will become shifted more appropriately-towards preventing falls in elderly people.

Pekka Kannus chief physician

Accident and Trauma Research Centre, UKK Institute, PO Box 30, FIN-33501 Tampere, Finland klpeka@uta.fi

Jaakko Kaprio professor

Department of Public Health and General Practice, University of Oulu, FIN-90220 Oulu, Finland

Markku Koskenvuo professor

Department of Public Health, University of Turku, FIN-20520 Turku, Finland

Mika Palvanen research fellow

Accident and Trauma Research Centre, UKK Institute, PO Box 30, FIN-33501 Tampere

Jari Parkkari chief physician

Research Centre of Sports Medicine, UKK Institute PO Box 30, FIN-33501 Tampere

\section{Improving the debate on cannabis}

\section{Let's find out whether cannabis has therapeutic value}

EDITOR-In discussions of the use of cannabis one of the biggest problems over the past few years has been the difficulty in separating the debate on the recreational use from that on the therapeutic use. The article by Strang et al also mixes the two issues. ${ }^{1}$

In all my years of working in pain relief I cannot remember the equivalent mix-up taking place over cocaine, morphine, heroin, etc. Although some matters occasionally overlap, the two main elements of the cannabis debate must remain in separate arenas. Only then can we educate politicians and the public about the facts and the real issues.

Meanwhile, let's get on and find out whether cannabis has significant and valuable therapeutic potential. This agent has been used medicinally for 5000 years and we still don't know whether it is therapeutically effective.

William Notcutt consultant anaesthetist James Paget Hospital, Great Yarmouth NR31 6LA willy@tucton.demon.co.uk

1 Strang J, Witton J, Hall W. Improving the quality of the cannabis debate: defining the different domains. $B M$ J 2000;320:108-10. (8 January.)

\section{Consider public welfare, not just public} health

EDITOR-Strang et al raise a number of salient issues in the debate over whether cannabis should be legalised. ${ }^{1}$ However, the eigh "domains of the cannabis debate" identified are centred exclusively on a public health conception of the relevant policy issues. Although this is understandable given the audience that the authors are addressing, they fail to consider more fundamental issues of what the public policy objectives should be when considering the recreational use of cannabis.

Their discussion reflects the fact that the medical profession has a natural tendency to judge the public regulation and legal contro of activities according to their impact on the health of the public. Thus, anything shown to be harmful to health is seen as inherently bad, while activities that promote health are seen as something to be encouraged by public institutions.

An alternative vision of the objective of public intervention and legislative structures is that they should exist to protect and improve public welfare as distinct from public health. Individual welfare is clearly affected by health but it also encompasses a broader class of personal benefits that people enjoy when freely undertaking specific activities (including using cannabis), even in cases in which they are knowingly exposing themselves to possible health risks.

This "welfarist" angle should not be confused with the libertarian line, which would espouse the removal of legal barriers that prevent people having the freedom to do as they wish. In the welfarist paradigm public regulation and control will always be required if the use of cannabis affects the welfare (including the health) of parties who are outside the decision to use. Public intervention is also needed to ensure that users are informed of any risks associated with use, even if this means telling people that at present the risks are largely unknown.

If it is accepted that health is only one aspect of individual welfare and that it is the responsibility of government to promote individual welfare even if in certain instances this means compromising health, then a public health driven debate will never offer satisfactory guidance on the desirability of the legal status quo of cannabis use.

Andrew Healey research officer

Department of Social Policy, London School of Economics and Political Science, London WC2A $2 \mathrm{AE}$ A.T.Healey@1se.ac.uk

1 Strang J, Witton J, Hall W. Improving the quality of the cannabis debate: defining the different domains. $B M$ J 2000;320:108-10. (8 January.)

\section{Social context should be added to} domains being considered

EDITOR-Strang et al argue that the cannabis debate has been oversimplified into polarised positions that consider cannabis to be either generally harmless and potentially therapeutic or harmful to health and consequently deserving of prohibition. ${ }^{1}$ To improve the quality of debate the authors usefully identify eight domains within which the health effects of cannabis should be examined. However, these domains represent only a narrow biological view of this difficult issue and focus almost exclusively on examining potentially negative effects. Further overarching domains, in particular of social context, need to be added to the debate.

Social opportunity costs arise as a result of criminalising cannabis users. These include their exclusion from school, university, and employment; incarceration; and blighting of their lives and careers as consequences of their becoming involved with criminal subcultures. Furthermore, cannabis use should be considered against the health consequences of alternative drugs, such as alcohol, which compete within a similar social niche. Current ethics do not provide an even handed assessment of alcohol-the drug of choice of large numbers of older people-and cannabis-the drug of choice of many younger people. Testing alcohol against Strang et al's domains is an informative exercise.

At the other end of the drug spectrum, cannabis legislation ties up disproportionate amounts of police and other judicial time. In 1998, of the 2240 police incidents directly involving drugs in Merseyside, $70.8 \%$ related to cannabis while heroin incidents accounted for only $6.3 \%{ }^{2}$ Consequently, the cost of current cannabis legislation also includes the diversion of judicial efforts away from drugs that have enormous repercussions for health.

Perhaps we can now begin to have an objective, evidence based, and inclusive discussion of the whole topic of alcohol and drug abuse, which includes tobacco, and which takes a social administration perspective in looking at the costs and benefits of social policy in full rather than being narrowly concerned with selective biological aspects.

John R Ashton regional director of public health NHS Executive North West, Warrington WA3 7QN

Mark A Bellis head of public health

Public Health Sector, Liverpool John Moores University, Liverpool L3 2AB

m.a.bellis@livjm.ac.uk

1 Strang J, Witton J, Hall W. Improving the quality of the cannabis debate: defining the different domains. $B M$ 2000:320:108-10. (8 January.)

2 Hardi L, Bellis MA. Merseyside interagency drug misuse database: a unified approach to drug misuse data. Liverpool:

\section{The effects of cannabis on driving are} difficult to evaluate

Editor-In their article on the cannabis debate, Strang et al raise the issue of cannabis and its effects on driving, suggesting that "a clearer understanding will be required of 
the extent to which a particular concentration of the drug (or its metabolites) can reliably be taken as evidence that an individual's driving ability was consequently impaired." A review of the literature, however, suggests that defining an acceptable level of cannabis consumption for driving is unlikely to be possible for several reasons.

Firstly, there is a poor correlation between plasma concentrations of trans- $\Delta$ tetrahydrocannabinol (THC) (the constituent of cannabis responsible for the production of most of the psychoactive response) after smoking and subjective, self reported psychological effects; plasma concentrations of THC decline long before peak effects are felt. ${ }^{2}$ Secondly, the relation between psychological testing and performance in experiments of real driving is complex because the two modalities of testing are different. Impairment in driving has been shown experimentally with acute intoxication by cannabis ${ }^{3}$; however attempts to correlate driving performance with concentrations of THC will be severely affected by the observed time lag between THC concentrations and peak effects.

The issue is further complicated in people who use cannabis heavily for prolonged periods. This group has been shown to develop tolerance to the somatic and psychological effects of THC; this tolerance cannot be correlated with any drop in concentration below that of users who are not tolerant. ${ }^{4}$ Chronic heavy users of cannabis do, however, show subtle impairment in memory, organisation, and attention, and the effect becomes more pronounced the longer the duration of use. ${ }^{5}$ Whether these effects diminish the ability to drive is not clear, but since they are unrelated to acute intoxication, it is unlikely that it will ever be possible to correlate them with concentrations of THC. Furthermore, it is not clear whether these abnormalities are reversible with prolonged abstinence.

The pursuit of a definition of a "safe" amount of cannabis that can be consumed and still allow for driving is unlikely to be successful.

Sarah Levy registrar in toxicology

Alison Jones consultant toxicologist

National Poisons Information Service (London),

Medical Toxicology Unit, London SE14 5ER

sarah.levy@gstt.sthames.nhs.uk

1 Strang J, Witton J, Hall W. Improving the quality of the cannabis debate: defining the different domains. $B M$ 2000;320:108-10. (8 January.)

2 Perez-Reyes M, DiGuiseppi S, Davis KH, Schindler VH, Cook CE. Comparison of effects of marijuana cigarettes of three different potencies. Clin Pharmacol Ther 1982;131 $617-24$.

3 Smiley A. Marijuana: on road and driving simulator studies. In: Kalant H, Corrigal W, Hall W, Smart R, eds. The health effects of cannabis. Toronto: Addiction Research Foundation, 1998

4 Hunt CA, Jones RT. Tolerance and disposition of tetra hydro cannabinol in man. J Pharmacol Exper Ther 1980;215:35-44.

5 Solowij N. Cannabis and cognitive functioning. Cambridge: Cambridge University Press, 1998.

\section{Emergency admissions in Stockport were exaggerated}

EDITOR-Morgan et al say that the increase in emergency admissions in Avon from
1989 to 1998 may be an artefact. ${ }^{1}$ Analyses in the annual public health report for Stockport reached a similar, but not identical, conclusion. $^{2}$

We found that the increases were exaggerated. Information distortions, interhospital transfers, increasing rates of admission for minor conditions, and changed patterns of flow affecting a particular provider unfairly accounted for almost two thirds of the apparent increase, leaving a true underlying pressure of $2.5 \%$ a year. Part of this increase was explained by changed practicefor example, improved management of chest pain-and part was unexplained.

The unexplained increase was entirely among elderly people. A rapid response scheme for acute care at home was put in place jointly by health and social services. For the first six months that the scheme was in place there was no year on year increase in emergency admissions for the population of Stockport. Since our original response last year, ${ }^{3}$ however, this halt has not been sustained and the pattern of emergency admissions has shifted towards younger age groups. This shift has not yet been fully analysed.

Patterns of emergency admission are complex. They require active management but this must not simply assume a constantly rising pressure. Investment in community services is relevant to a whole system approach.

Stephen J Watkins director of public health stephen.watkins@stockport-ha.nwest.nhs.uk Sue Alting head of health service development Department of Public Health, Stockport Health Authority, Springwood House, Stockport SK7 5BY

1 Morgan K, Prothero D, Frankel S. The rise in emergency admissions-crisis or artefact? Temporal analysis of health admissions-crisis or artefact? Temporal analysict

2 Watkins SJ. Health 2000; four years to go. 8th annual publi health report for Stockport. Stockport: Stockport Healt Authority, 1996:363-403.

3 Electronic response. The rise in emergency admissionscrisis or artefact? Temporal analysis of health services data. bmj.com 1999. bmj.com/cgi/eletters/319/7203 158 \#LL5 (accessed 10 June).

\section{Number of embryos allowed in fertility treatment should be flexible}

EDIToR-The Royal College of Obstetricians and Gynaecologists' new guidelines for the management of infertility in tertiary care $^{1-3}$ are generally welcomed. Guideline 10 , however, recommends that the maximum number of embryos should be reduced from three to two for all patients. This is an imprecise way of dealing with a complex problem, eliminating triplets at the expense of some couples having their own child. Regulatory authorities already deprive some women of having their own children because of the decision to fix the upper limit to three in 1987. The college should have evaluated who is at risk of having a multiple pregnancy and made recommendations based on this risk.

A fertility index based on factors associated with the risk of having a multiple preg- nancy could be calculated to determine how many embryos to transfer. This should result in women with high reproductive potential receiving one or two embryos and those with low reproductive potential receiving three or even more. We have indirect evidence to support this reasoning. Using gamete intrafallopian transfer, we have transferred more than three eggs to women aged $>40$ who have a low risk of multiple pregnancy; this technique does not come under the supervision of the Human Fertilisation and Embryology Authority. Our live births/ongoing pregnancies for those aged $41-44$ is $15 \%$, compared with about $4.8 \%$ from the authority's national data on in vitro fertilisation, and there were no triplets.

We believe that the college's recommendation is flawed. If transferring two rather than three embryos in women aged $\leqslant 40$ gives the same chance of a singleton pregnancy there should be a comparable singleton pregnancy rate between centres with different incidences of two embryo transfers. Analysis of data from the Human Fertilisation and Embryology Authority for all ages in 1999 indicates very different rates between our centre (12\% two embryo transfer) and centres having a higher incidencefor example, Aberdeen (63\%) and Hammersmith Hospital (52\%). ${ }^{2}$ The differences were not simply due to an increase in multiple pregnancy-mostly twin pregnancies. The chance of having a birth per embryo transfer for all treatments, including the use of frozen embryos, was greater in our centre (19.5\% compared with $14.4 \%$ and $12.5 \%$ respectively); the chance of a singleton birth was $13.3 \%$ compared with $11.1 \%$ and $9.9 \%$.

Guideline 10 also states erroneously that there is a significant risk of triplets in women over 40 when three embryos are transferred, but the Human Fertilisation and Embryology Authority's data indicate just one set in 808 transfers. The college should acknowledge that infertile women have different reproductive potentials and risks of multiple pregnancy; it should amend its recommendation to allow for flexibility rather than have patients fit an inappropriate and incorrect medicopolitical dogma.

Ian Craft professor

Barbara Podsiadly laboratory manager

A Gorgy gynaecologist

G Venkat gynaecologist

London Gynaecology and Fertility Centre, London W1N $1 \mathrm{AF}$

1 Kmietowicz Z. College urges maximum of two embryos for in vitro fertilisation. BMJ 2000;320:271. (29 January.)

2 Human Fertilisation and Embryology Authority. 1999 HFEA patient guide. London: HFEA, 1999

3 Royal College of Obstetricians and Gynaecologists. The management of infertility in tertiary care. London: RCOG, 2000. (Evidence based clinical guideline No 6 .

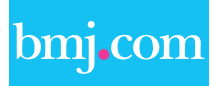

Rapid responses

Correspondence submitted electronically is available on our website 